\title{
Küresel Covid-19 Salgınının Türkiye Sağlık Sigortası Sektörüne Etkisi
}

\author{
The Effect of The Covid-19 Pandemic on Turkey Health Insurance Sector
}

\section{Öz}

Bir risk transfer sistemi olan sigorta, zararı paylaşılmakta olan tehlikenin odaklandiğ yere göre branşlara ayrilmaktadır. Sigorta branşları, kaza, ferdi kaza, hastalık/să̆lık, kara/su araçları, nakliyat, yangın ve doğal afetler, genel zararlar, kara araçları sorumluluk, genel sorumluluk, kredi ve borcun ödenmemesi sigortasl, finansal kayıplar, hukuksal koruma ve hayat olarak stralanabilir.

Bu çalışmanın amacı Covid-19 küresel salgınının Türkiye'de sağlık sigortasi sektöründeki etkilerini incelemektir. Inceleme Ocak 2019-Aralı 2020 dönemi ele alınarak ve alt branş bazında teminat adetleri incelenerek gerçekleştirilmiştir. Yapılan incelemeler sonucunda Covid-19 salgınına ilişkin Türkiye'de ilk vaka tespitinin yaşandiğı Mart 2020'den sonra, Nisan, A ğustos, Ekim ve Aralık aylarında ele alınan sağlık sigortalarının artış gösterdiği söylenebilir. Öte yandan sigorta şirketlerinin sağlık sigortalarmın kapsamları detaylı bir şekilde incelenerek çalışmada gözlenen artışların küresel salgınla bağlantısı noktasında ayrıntılı ve kesin yorumlar yapulabilecektir

\section{Abstract}

As a risk transfer system, insurance is divided into branches according to the focus of danger of which harm is being shared. Insurance branches can be listed as accident, personal accident, illness/health, land/water vehicles, transportation, fire and natural disasters, general damages, land vehicles liability, general liability, credit and non-payment insurance, financial losses.

The aim of this study was to investigate the effects of the Covid-19 pandemic in the health insurance sector in Turkey. The examination was carried out by considering the period of January 2019-December 2020 and by examining the number of collaterals on the basis of sub-branches. Considering these changes mentioned it can be said that after March 2020 that the first case occurred in that the finding of a Covid-19 pandemic in Turkey, in April, August, October and December the health insurances increased. On the other hand, by examining the coverage of health insurances of insurance companies in detail, detailed and definitive comments can be made on the connection between the increases observed in the study and the pandemic.

\section{Giriş}

Sigorta bir risk transfer sistemi olup, sigorta işlemine konu olan tehlikeyle karşılaşanların, söz konusu tehlikenin meydana gelmesiyle fiilen zarara uğramaları durumunda zararını karşılamada kullanmak amacıyla belirli bir miktar para ödemesi yoluyla toplanan tutarlar temelinde oluşumunu tamamlamaktadır. Sigortanın temel işlevi, zararı ekonomik açıdan önemsiz bir duruma getirilmesi ve tehlikeyle karşılaşanların tek başına karşılayamayacakları zararların bir organizasyon paylaşılmasını sağlamaktır (TSB, 2021d).

Sigorta zararı paylaşılmakta olan tehlikenin odaklandığı yere göre branşlara ayrılmaktadır. Sigorta branşları, kaza, ferdi kaza, hastalık / sağlık, kara / su araçları, nakliyat, yangın ve doğal afetler, genel zararlar, kara araçları sorumluluk, genel sorumluluk, kredi ve borcun ödenmemesi sigortası, finansal kayıplar, hukuksal koruma ve hayat olarak siralanabilir (TSB, 2021e).

\author{
M. Esra Atukalp \\ Dr. Ür. Uyesi, Giresun Üniversitesi, \\ Yüksekokulu, Uluslararası Ticaret ve \\ Orcid No: https://orcid.org/0000-0001- \\ 8412-1448
}

Anahtar Kelimeler

Keywords

Health Insurance, Turkey, Covid-19 Pandemic

Submitted: $\quad 09 / 03 / 2021$

Accepted: $\quad 04 / 08$ / 2021
Article Type/Makale Türü 
Finans sektörünün önemli bir aktörü olan sigorta sektörü ekonominin gelişiminde önemli bir role sahip olmasının yanı sıra aktörü olduğu ekonominin bileşenlerinden ve küresel değişimlerden de etkilenmektedir. Dünya genelinde olduğu gibi Türkiye'de de görülen küresel Covid-19 salgını, başta sağlık sistemi olmak üzere, ülkelerde önemli sonuçlara neden olmuştur. Küresel salgın, belirtildiği gibi en önce sağlık sektörünü etkisi altına almış olup, bunun yanı sıra ekonomide var olan tüm sektörleri etkilemiştir ve bütünüyle ülke ekonomilerinde önemli etkileri olmuştur.

Ülkelerde yaşamakta olan bireyler bu kapsamda sağlık yapılanmasının bir unsuru olan sigortaya ilişkin girişimlerde bulunmuşlardır. Bu durum da sigorta sisteminde değişikliklere neden olabilmektedir. Küresel Covid-19 salgınının Türkiye'de sağlık sigortasında neden olduğu değişimi inceleyen bu çalışma, sağlık sigortasına ilişkin analiz bulgularının yer aldığı iki bölümden oluşmaktadır.

\section{Sağlık Sigortası Sektörü Üzerine İnceleme}

Sigorta, zararı paylaşılmakta olan tehlikenin odaklandığı yere göre branşlara ayrılmaktadır. Sigorta branşı adları; kaza, hastalık / sağlık, kara / raylı / hava / su araçları, nakliyat, yangın ve doğal afetler, genel zararlar, kara / hava / su araçları sorumluluk, genel sorumluluk, kredi, kefalet, finansal kayıplar, hukuksal koruma ve hayat olarak siralanabilir (TSB, 2021e). Sigortacilık sektöründe sağlık sigortası ve seyahat sağlık sigortası; sağlık branş toplamı altında ise acil sağlık, yabancılar için sağlık, tamamlayıcı sağlık, sağlık ve seyahat sağlık alt branşları yer almaktadır.

Türkiye Sigorta Birliği (TSB) verilerinde sağlık branşı toplamı, acil sağlık, yabancılar için sağlık, tamamlayıcı sağlık ve sağlık alt branşlarından oluşmaktadır. Tamamlayıcı sağlık ve sağlık alt branşları ise yatarak ve ayakta tedavi seçeneklerine sahiptir.

Sağlık sigortası kişilerin, tıbbi yardım, tedavi ve ilaç harcamalarına karşı teminat veren sigorta türüdür. Sigortalının, ameliyat, uzun veya kısa süreli tedaviler, ameliyat veya tedaviye bağlı ilaç giderleri gibi tüm harcamaları, azami limitlerle tam veya muafiyet olarak karşılanmaktadır (TSB, 2021b). Seyahat sağlık sigortası ise yurt içinde, yurt dışına veya yurt dışından ülkemize, ulaşım yollarından herhangi birisini kullanarak seyahat edenleri, seyahatleri esnasında karşılaşabilecekleri sağlık risklerine karşı koruyan bir özel sigorta türüdür (TSB, 2021c)

Sağlık sigortası uygulamalarında sigorta şirketlerinin uygulamalarında farklılıklar olabilmektedir. Küresel Covid-19 salgınına ilişkin olarak sigorta şirketlerinin sağlık sigortalarının kapsamlarında değişikler yapması, diğer bir ifade ile Covid-19 tedavisi sürecine ilişkin uygulamaları sigorta kapsamına alması söz konu olmaktadır. Bu doğrultuda da salgın döneminde sağlık sigortasına ilişkin verilerde değişikliğin gözlenmesi muhtemel olmaktadır.

\subsection{Literatür İncelemesi}

Küresel Covid-19 salgınının sigortacılık, sigorta hukuku, ticaret, turizm vb. sektörlere etkilerini inceleyen akademik çalışmalar bulunmaktadır. Çalışma kapsamında sigorta sektörüne etkilerini inceleyen çalışmalar başta olmak üzere Covid-19'un etkileri üzerine yapılan çalışmalardan bazıları şunlardır:

- Covid-19'un Gana sigorta endüstrisi üzerindeki etkisini inceleyen Babuna vd. (2020)'nin çalışması,

- Covid-19’un Çin sigorta piyasasındaki etkilerini inceleyen Wang vd. (2020)'nin çalışması,

- Xu vd. (2020)'nin Covid-19'un Çin' de yaşlılar arasında ticari uzun süreli bakım sigortası alma niyetine etkisini inceleyen çalışması,

- Demir (2020)'nin Covid-19'un BİST 100'deki şirketlerin mali tabloları üzerindeki etkisini inceleyen çalışması,

- Kaynak (2020)'ın koronavirüs algısının online alışverişe etkisi üzerine yaptığı çalışması,

- Durmuş ve Şahin (2020)'in Covid-19 küresel salgında dünyada ve Türkiye'de uygulanan ekonomi politikaları üzerine değerlendirme yaptıkları çalışmaları,

- Fidan (2020)'nin dört büyük kriptoparanın piyasa riskinde Covid-19 pandemi etkisini ele aldı ̆̆ı çalışması,

- Güler (2020)'in koronavirüsü salgınında bankalara iletilen müşteri itiraz ve şikayetlerini incelediği çalışması, 
- Telli Danışmaz (2020)'ın Covid-19 salgınının tüketicilerin online alışveriş tercihine etkisini ele aldığı çalışması,

- Işık Erol (2020)'un İtalya, İspanya ve Türkiye örnekleri üzerinden Covid-19'un turizm sektöründe istihdama etkisini ele aldıkları çalışması,

- Bayraktar (2020)'nin BİST imalat sektörü hisse senetleri üzerinde Covid-19 pandemisinin etkisini incelediği çalışması.

\subsection{Veri Seti}

Sigortacılık sektöründe sağlık sigortası ve seyahat sağlık sigortası branşları, sağlık branş toplamı altında ise acil sağlık, yabancılar için sağlık, tamamlayıcı sağlık, sağlık ve seyahat sağlık alt branşları yer almaktadır.

İnceleme Ocak 2019 - Aralık 2020 dönemi ele alınarak ve sağlık alt branşları bazında teminat adetleri incelenerek gerçekleştirilmiştir. Araştırmaya ilişkin verilere TSB internet sitesinden ulaşılabilmekte olup, incelemede sağlık branşı toplamı, tamamlayıcı sağlık alt branşı ve sağlık alt branşı dikkate alınmıştır.

Sektörde toplam prim üretimindeki değişimin teminat ve sigortalı adedindeki değişimler benzerlik göstermediği noktalar bulunmaktadır. Örneğin, TSB (2021a) toplam prim üretimi verileri incelendiğinde teminat adedinde Nisan 2020 'de söz konusu olan önemli artış, prim üretiminde söz konusu değildir. Bu durum, sigorta firmaların bünyesinde söz konusu olabilecek prim indirimlerine (Yıldırım, 2020: 5) bağlanabilir. Çünkü söz konusu dönemde sigorta yaptıran sigortalı adedi artarken, toplam prim tutarında teminat adedindeki artışla paralel bir değişim meydana gelmemiştir. Buradan sektörün, Covid-19'dan sigorta miktarı bazında etkilenme düzeyinin teminat adedindeki değişimin ele alınması suretiyle izlenmesinin daha yerinde olabileceği ortaya çıkabilir.

\section{Bulgular}

Ocak 2019 - Aralık 2020 döneminde sağlık alt branşları bazında teminat adetlerinin incelenmesi sonucu elde edilen bulgular bu başlık altında verilmektedir. İncelemelerde sigorta adedi ya da Türk Lirası cinsinden üretim verileri tercih edilmemiş bunun yerine teminat adedi verileri incelenmiştir. Bunun nedeni sigorta şirketlerinin yıl sonlarında çeşitli sebeplerle yapmış oldukları kampanyaların bu değerlerde değişime neden olacağı ve bunun da müşterilerin sigorta yapma eğilimindeki değişiklikten ziyade sigorta firmalarının pazarlama faaliyetleri sonucunda ortaya çıkan bir eğilim sonucu olacağı düşüncesidir. Bu nedenle bu verilerin ele alınmasının sektöre ilişkin ortaya konulan tablonun objektifliğinin önüne geçebileceği, sigorta müşterilerinin sigorta yapma tercihinin yanı sira fiyat taktikleri doğrultusunda değişimin etkilenebileceği nedeniyle bu veriler tercih edilmemiştir.

Grafik 1'de sağlık alt branşları teminat adedinde verilen kümülatif değerlerden yararlanılarak elde edilen aylık verilere ilişkin değişim yüzdeleri verilmektedir. Sağlık alt branş teminat adedinde aylık değişimlerin dağılımları Grafik 1'de verilmiştir. 


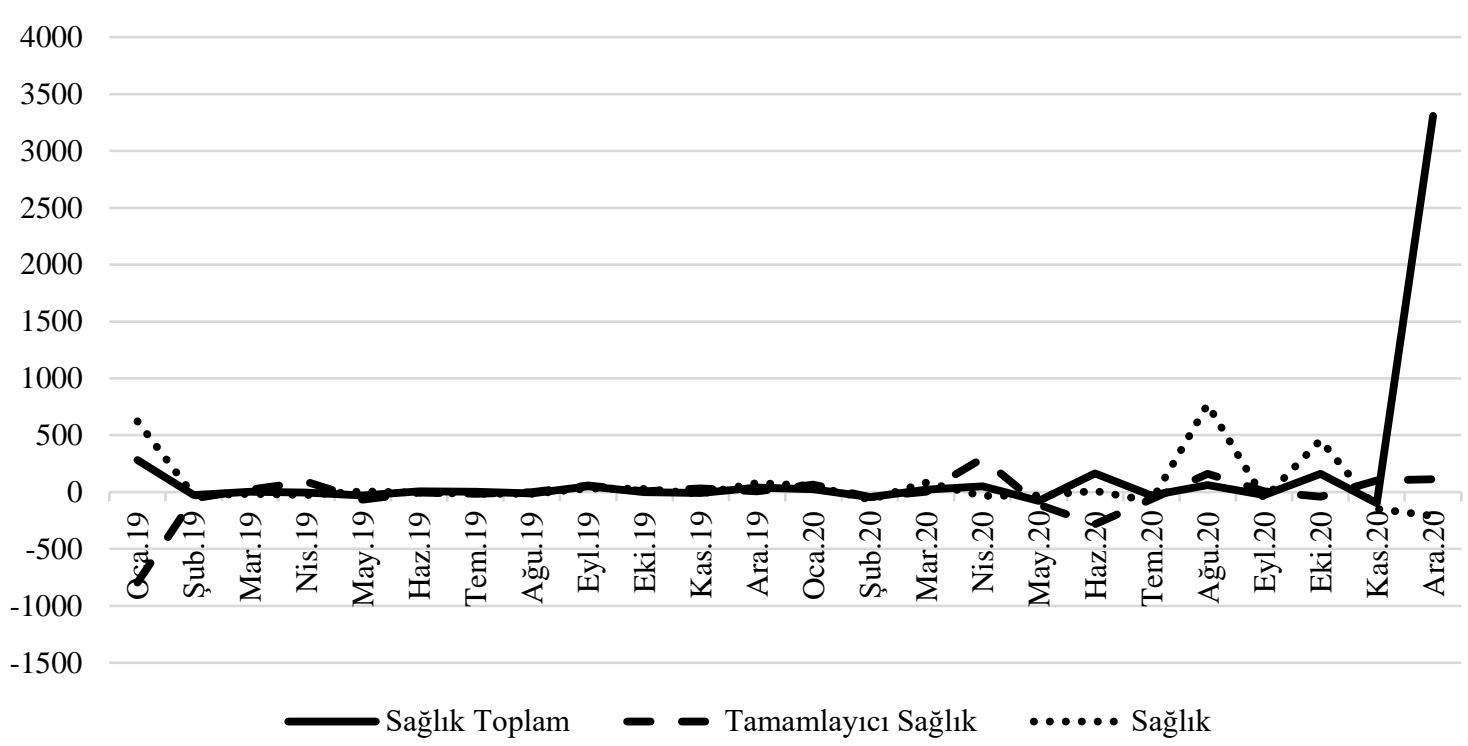

Grafik 1. Sağlık Alt Branş Teminat Adedinde Aylık Değişim (\%)

Kaynak: TSB, 2021a verilerinden yararlanılarak hazırlanmıştır.

Grafik 1'de teminat adedi artışı incelendiğinde; Nisan 2020' de tamamlayıcı sağlık alt branşında teminat adedinin \%297 değerinde bir artışla, 148.584'dan 589.195'e yükseldiği görülmektedir. Ancak branşta benzer oranda bir azalış Haziran 2020'de meydana gelmiştir. Sağlık alt branşında ise Ağustos 2020'de ve Ekim 2020'de sırasıyla \%772 ve \%457'lik bir artış meydana gelmiştir. Tüm alt branşların toplamını oluşturan sağlık branşı toplamında ise 37.336 olan teminat adedi artarak Aralık 2020 'de 1.272.288'e yükselmiştir. Bahsedilen bu değişimler ele alındığına Covid-19 salgınının Türkiye'de ilk vaka tespitinin yaşandığı Mart 2020'den sonra Nisan, Ağustos, Ekim ve Aralık aylarında artış gösterdiği söylenebilir. Alt branş teminat adedinde aylık değişimlerin dağılımları Grafik 2' de verilmiştir

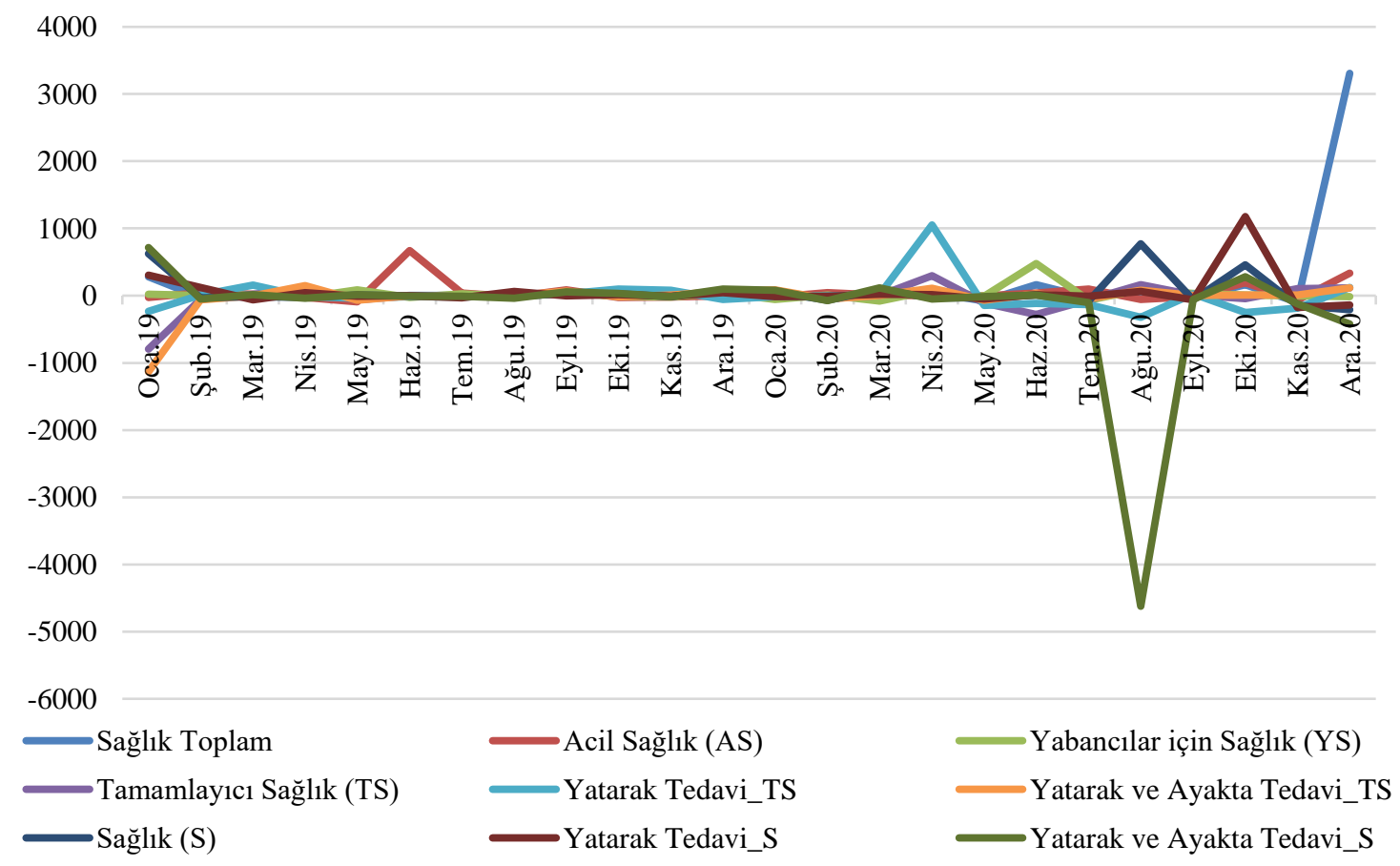

Grafik 2. Alt Branş Teminat Adedinde Aylık Değişim (\%) (Tüm Branşlar)

Kaynak: TSB, 2021a verilerinden yararlanılarak hazırlanmıştır. 
Grafik 2' de yer alan tüm branşlara ilişkin veriler incelendiğinde; sağlık ve tamamlayıcı sağlık alt branşına ilişkin değişimlerin hangi alt branştaki teminat adedinden kaynaklandığ 1 incelenebilir.

Grafik 3'te sağlık alt branşında teminat adedinin dağılımı Ocak 2019-Aralık 2020 dönemi itibariyle gösterilmektedir. Sigorta üretiminin mevsimsel, dönemsel olarak değişkenlik gösterebilmesi, grup yazılan poliçelerin iptal edilebilmesi ve dönemsel iptallerden kaynaklı azalışlar yaşanabilmektedir.

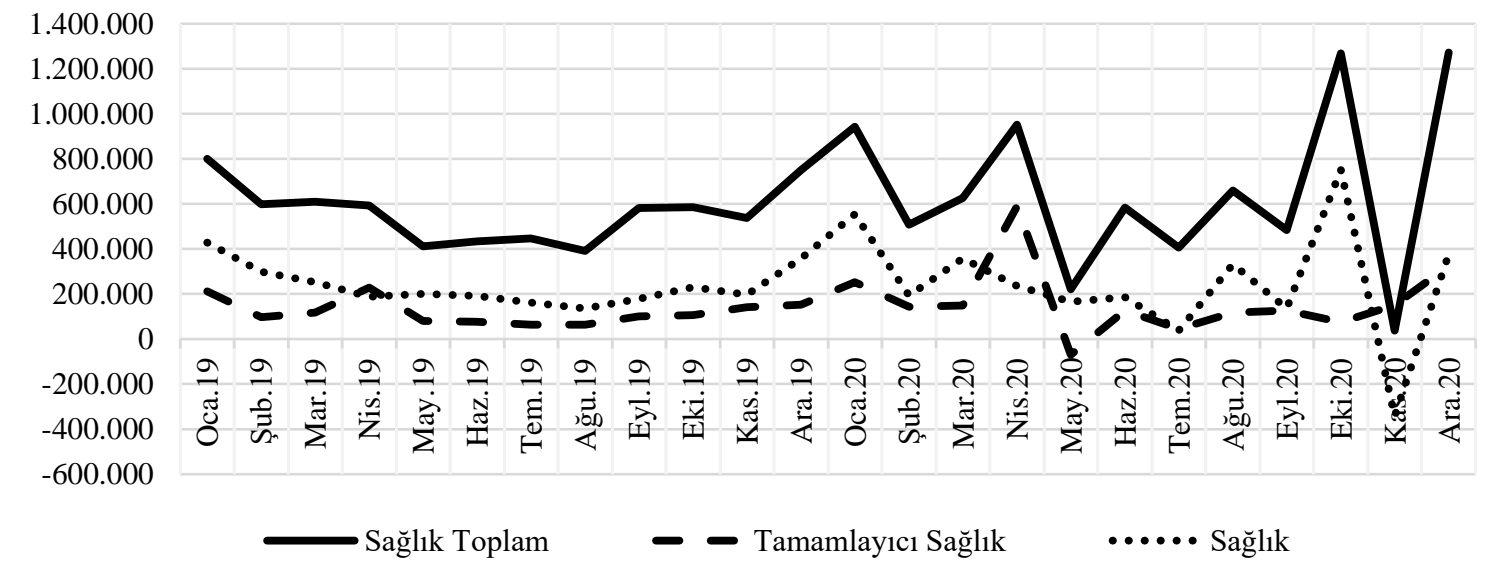

Grafik 3. Sağlık Alt Branş Teminat Adedi

Kaynak: TSB, 2021a verilerinden yararlanılarak hazırlanmıştır.

Grafik 3’te de görüldüğü gibi 2020 yılında Ocak, Nisan, Ekim ve Aralık ayında sağlık branşları toplamında teminat adedinde miktar artışı söz konusudur. Bu artış Grafik 4'te yer alan tüm branş verilerinde görüldüğ ü gibi özellikle tamamlayıcı sağlık branşındaki teminat adedindeki artıştan kaynaklanmaktadır. 2020 yılında meydana gelen artışın 2019 yılında söz konusu olmaması, söz konusu sigortalarda küresel salgından kaynaklı bir artışın söz konusu olabileceğini gösterebilir. Sağlık alt branşında yer alan tüm diğer alt branşların teminat adetleri ise Grafik 4 'te verilmiştir.

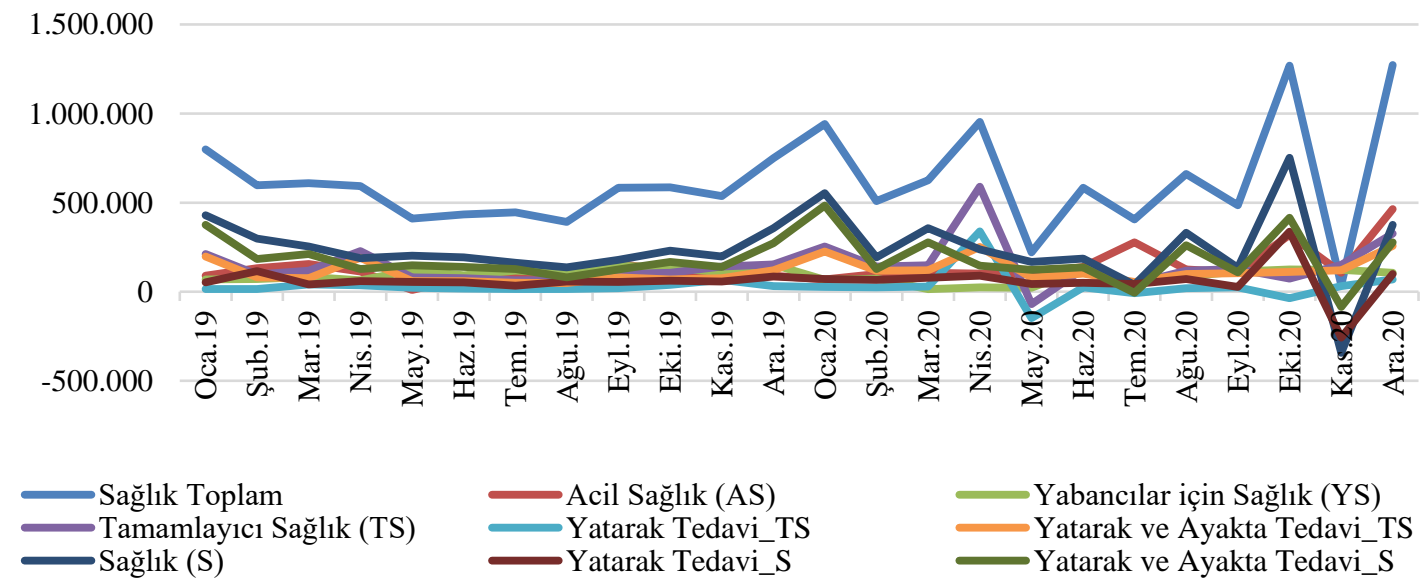

Grafik 4. Sağlık Alt Branş Teminat Adedi (Tüm Branşlar)

Kaynak: TSB, 2021a verilerinden yararlanılarak hazırlanmıştır.

\section{Sonuç ve Değerlendirme}

Yapılan incelemeler sonucunda teminat adedinin Nisan 2020'de tamamlayıcı sağlık alt branşında, Ağustos 2020'de ve Ekim 2020'de ise sağlık alt branşında önemli yüzdelerle artış gösterdiği görülmektedir. Tüm alt branşların toplamını oluşturan sağlık branşı toplamında Aralık $2020^{\prime}$ de teminat adedinin önemli yüzdelerle arttı̆̆ı görülmektedir. Bahsedilen bu değişimler ele 
alındığına Covid-19 salgınına ilişkin Türkiye' de ilk vaka tespitinin yaşandığı Mart 2020' den sonra Nisan, Ağustos aylarında ve salgına ilişkin 2. önemli yayılımın ifade edildiği Ekim ve Aralık aylarında ele alınan sağlık sigortalarının artış gösterdiği söylenebilir. 2020'nin ilgili aylarında meydana gelen artışın 2019 döneminin aynı aylarında söz konusu olmaması, bu artışların dönemsel rutin bir değişimden ileri gelmediğini göstermekte ve küresel salgın sonucu sigorta yaptırma eğiliminin bir sonucu olduğunu düşündürmektedir.

Öte yandan sigorta şirketlerinin sağlık sigortalarının kapsamları detaylı bir şekilde incelenerek, Covid-19 vb. salgınları sigorta kapsamına alma durumları değerlendirilmelidir. Sigorta kapsamlarına ilişkin bu detaylı inceleme sonucunda, çalışmada gözlenen artışların küresel salgınla bağlantısı noktasında ayrıntılı ve kesin yorumlar yapılabilecektir.

\section{Kaynakça}

Babuna, P., Yang, X., Gyilbag, A., Awudi, D. A., Ngmenbelle, D. \& Bian, D. (2020). The impact of COVID-19 on the insurance industry. International Journal of Environmental Research and Public Health, 17(16), 1-14.

Bayraktar, A. (2020). Covid 19 pandemisinin finansal etkileri: BİST imalat sektörü uygulaması. Turkish Studies, 15(8), 3415-3427.

Bryan, A. F. \& Tsai, T. C. (2021). Health insurance profitability during the Covid-19 pandemic. Annals of Surgery, 273(3), 88-90.

Demir, Z. (2020). Covid-19'un BİST 100'deki şirketlerin mali tabloları üzerindeki etkisinin oran yöntemi ile analizi. Hitit Üniversitesi Sosyal Bilimler Enstitüsü Dergisi, 13(2), 439-465.

Durmuş, S. \& Şahin, D. (2020). Covid-19 küresel salgında dünyada ve Türkiye'de uygulanan ekonomi politikaları üzerine bir değerlendirme. Turkish Studies, 15(4), 923-943.

Fidan, N. (2020). Dört Büyük Kriptoparanın Piyasa Riskinde Covid-19 Pandemi Etkisi. Ekonomi Politika ve Finans Araştırmaları Dergisi, 5(Özel Sayı), 206-224.

Güler, H. N. (2020). Koronavirüsü (Covid-19) günlerinde bankalara iletilen müşteri itiraz ve şikayetlerinin incelenmesi. Avrasya Sosyal ve Ekonomi Araştırmalan Dergisi, 7(4), 85-99.

Işık Erol, S. (2020). Covid-19'un Turizm Sektöründe İstihdama Etkisi: İtalya, İspanya ve Türkiye Örnekleri. Işletme ve İktisat Çalışmaları Dergisi, 8(2), 38-49.

Kaynak, İ. (2020). Koronavirüs (Covid-19) Algısının Online Alışverişe Etkisi. Turkish Studies, 15(4), 633-645.

Telli Danışmaz, A. (2020). Covıd-19 Salgınının Tüketicilerin Online Alışveriş Tercihine Etkisi. Sosyal Bilimler Araştırma Dergisi, 9(2), 83-90.

Türkiye Sigorta Birliği-TSB (2021a). Resmi Istatistikler, Güncel Sigorta Verileri. [Çevrim-içi: https://www.tsb.org.tr/resmi-istatistikler.aspx?pageID=909], Erişim tarihi: 19.02.2021.

Türkiye Sigorta Birliği-TSB (2021b). Sağlık Sigortası. [Çevrim-içi: https://www.tsb.org.tr/sagliksigortasi.aspx?pageID=625 (19.02.2021).

Türkiye Sigorta Birliği-TSB (2021c). Seyahat Sağllk. [Çevrim-içi: https://www.tsb.org.tr/seyahatsaglik.aspx?pageID=626], Erişim tarihi: 19.02.2021.

Türkiye Sigorta Birliği-TSB (2021d). Sigorta Tamımları. [Çevrim-içi: https:/ / www.tsb.org.tr/sigortatanimlari.aspx?pageID=648], Erişim tarihi: 20.02.2021.

Türkiye Sigorta Birliği-TSB (2021e). Sigorta Branşları. [Çevrim-içi: https:/ /www.tsb.org.tr/sigortabranslari.aspx?pageID=622], Erişim tarihi: 20.02.2021.

Wang, Y., Zhang, D., Wang, X. \& Fu, Q. (2020). How does Covid-19 affect China's insurance market? Emerging Markets Finance and Trade, 56(10), 2350-2362.

Xu, X., Zhang, L., Chen, L. \& Wei, F (2020). Does Covid-2019 have an impact on the purchase intention of commercial long-term care insurance among the elderly in China? Healthcare, 8(2), $1-17$.

Yıldırım, A. H. (2020). Covid-19 salgını nedeniyle sigorta primlerinin indirilmesi ve iadesi sorunu. Yaşar Hukuk Dergisi, 2(2), 1-8. 


\section{Aim and Scope}

\section{Extended Abstract}

Insurance is a risk transfer system. In other words, it is a system where the amount collected as a result of paying a certain amount of money by those who encounter danger is used to compensate the losses of those who suffer damage as a result of the occurrence of the danger. Insurance is divided into branches according to the focus of danger of which harm is being shared. Insurance branches can be listed as accident, personal accident, illness / health, land / water vehicles, transportation, fire and natural disasters, general damages, land vehicles liability, general liability, credit and non-payment insurance, financial losses, legal protection and life. The aim of this study was to investigate the effects of the Covid-19 pandemic in the health insurance sector in Turkey.

\section{Methods}

The examination was carried out by considering the period of January 2019-December 2020 and by examining the number of collaterals on the basis of sub-branches. Under sum health insurance in insurance industry, the datas on health emergency, health care for foreigners, complementary health and health sub-branches are accessible from Turkey Insurance Association website and health insurance in total, complementary health sub-branches and health sub-branch was taken into account in the review.

\section{Findings and Conclusions}

As a result of the examinations, it is seen that the number of coverage increased in the complementary health sub-branch in April 2020, and in the health sub-branch in August 2020 and October 2020 with significant percentages. It is seen that the number of coverage increased with significant percentages in December 2020 in the total of the health branches that make up the total of all sub-branches. Considering these changes mentioned it can be said that after March 2020 that the first case occurred in that the finding of a Covid-19 pandemic in Turkey, in April, August, October and December the health insurances increased. The fact that the increase occurring in the relevant months of 2020 did not occur in the same months of the 2019 period indicates that these increases did not result from a periodic routine change and suggest that they are a result of the tendency to insure as a result of the pandemic. On the other hand, the coverage of health insurances of insurance companies was examined in detail, and the situation of insuring Covid-19 etc. pandemics should be evaluated. As a result of this detailed examination of insurance coverage, detailed and definitive comments can be made on the connection between the increases observed in the study and the pandemic. 